\title{
Analysis of a Five-Phase PM Vernier Machine Topology with Two-Slot Pitch Winding
}

\author{
Shaohong Zhu \\ Institute for Aerospace Technology, \\ University of Nottingham, \\ Nottingham, UK \\ ezzsz@nottingham.ac.uk \\ Chris Gerada \\ Power Electronics, Machines and \\ Control Research Group, \\ University of Nottingham, \\ Nottingham, UK \\ eezcg@nottingham.ac.uk
}

\author{
Tom Cox \\ Power Electronics, Machines and \\ Control Research Group, \\ University of Nottingham, \\ Nottingham, UK \\ ezztc@nottingham.ac.uk
}

\author{
Zeyuan Xu \\ Power Electronics, Machines and \\ Control Research Group, \\ University of Nottingham, \\ Nottingham, UK \\ epzzx@nottingham.ac.uk
}

\begin{abstract}
This paper presents a five-phase permanent magnet (PM) vernier machine topology equipped with a two-slot pitch winding. The two-slot pitch winding provides a trade-off between fractional slots concentrated winding (FSCW) and integrated slot distributed winding (ISDW) PM vernier machines. First, the development and basic structure of the fivephase PM vernier machine with auxiliary teeth are depicted. Then, the PM vernier machine with proposed two-slot pitch fractional slot winding is explained. Finally, the five-phase PM vernier machines with conventional ISDW and FSCW configuration are analyzed and compared with the proposed PM vernier machines with two-slot pitch fractional slot winding. The benefits of introducing two-slot pitch windings are quantitatively analyzed and verified by finite-element analysis (FEA). This analysis confirms that a higher back EMF and torque density can be achieved in this topology while keeping a reasonable power factor.
\end{abstract}

Keywords-Five-phase, gear ratio, permanent magnet (PM) vernier machine, space harmonics, two-slot pitch winding

\section{INTRODUCTION}

Permanent magnet (PM) vernier machines have become promising candidates in low-speed high torque applications due to their high torque density and suitability for low speed operation [1] [2].

The PM vernier machine can be seen as a single airgap field-modulated machine, which was firstly studied in [1] [2], where the design and operational principle have been presented; and their higher torque density capability due to the field modulation or magnetic gearing effect has been explained. However, a general characteristic of poor power factor was also identified for these machines. An analysis of torque quality and capability was undertaken in [3]. In addition, extensive studies have been explored to the further increase torque density [4]-[6]. In [6], a novel PM vernier machine with unevenly distributed auxiliary teeth has been proposed which gives extra working harmonics to generate higher back EMF and consequently a higher output torque. Serval novel PM vernier machine topologies have been proposed to improve the power factor. A PM vernier machine topology with flux barrier in the spoke-array PM rotor is investigated in [7], which provides an extra flux route for the fundamental harmonic and consequently improves the output torque.

There have been several papers working on improving the power factor [7]-[9]. In [9], a double stator spoke-array PM vernier machine was presented and a power factor of 0.85 can be achieved. Generally, the power factor could be improved to 0.8 or even 0.9 if a spoke-array rotor topology is used. This is attributing to their flux-concentrated effect improving back EMF and a thicker magnet thickness gives a lower reactance.

However, the extensive usage of rare earth magnets causes a significant challenge in terms of cost and manufacturing complexity for industry. Consequent-pole or spoke-array with ferrite magnet becomes popular in dealing with the cost issue [7] [10]. A comparable torque capability can be achieved but with the compromise of relatively poor power factor [10].

On the other hand, the winding configuration has a significant effect on the gear ratio of the PM vernier machine which in turn will impact the torque capability and power factor [11] [12]. In [11], the effects of the gear ratio and the winding pole pair numbers on the torque capacity and power factor have been studied, revealing the significant influence of gear ratio on the performance and optimal design parameters. A PM vernier machine comparison between fractional slots concentrated winding (FSCW) and integrated slot distributed winding (ISDW) was presented [12], which indicates that the ISDW configuration features a much higher torque density.

In this paper, a five-phase permanent magnet (PM) vernier machine topology equipped with two-slot pitch winding is proposed, which can be regarded as a compromise solution between the FSCW and ISDW PM vernier machine. The development and operational principle of PM vernier machine will be introduced before presenting the novel two-slot pitch fractional slot winding configuration. Several applicable combinations will be summarized. The performance comparison with conventional ISDW and FSCW configuration will be studied to demonstrate the superiority of the proposed PM vernier machine with two-slot pitch winding in terms of torque capability and power factor.

\section{PM VERNIER MACHINE TOPOLOGY AND THEORETICAL ANALYSIS}

\section{A. Development of PM Vernier Machine with Evenly Distributed Auxiliary Teeth}

A double airgap magnetically geared (MG) or fieldmodulated machine is shown in Fig. 1. The iron pole-piece ring and PM ring can be rotating or static. Depending on the different motion type, a double rotor or double stator FM machine can be obtained. For the double stator configuration, 
the inner stator can be either iron pole-piece ring or PM ring. If both the slotted stator and iron pole-piece ring are static, a PM vernier with auxiliary teeth is achieved when removing the outer airgap and combining the iron pole-piece with slotted stator. Therefore, a PM vernier machine can be recognized as a single-airgap field-modulated machine, where all the iron pole-pieces are combined with the slotted stator.

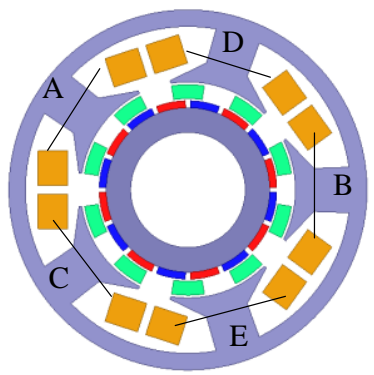

(a)

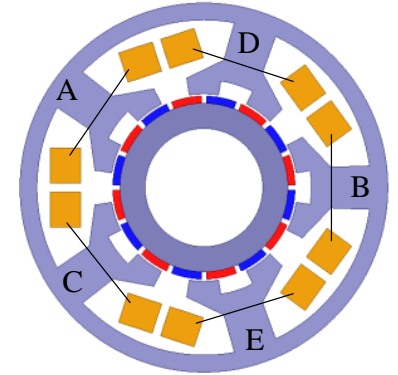

(b)
Fig. 1. (a) Five-phase double airgap field modulated PM machine (b) Five-phase PM vernier machine with auxiliary teeth.

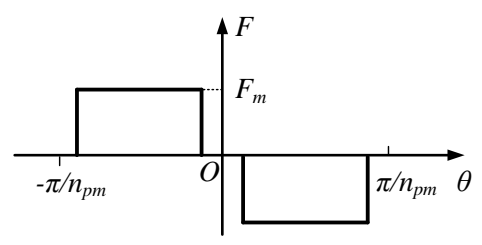

Fig. 2. MMF of rotor PM.

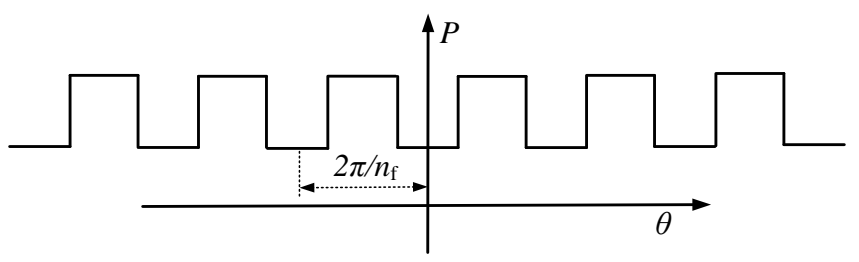

Fig. 3. Airgap permeance due to auxiliary teeth $\left(n_{\mathrm{a}}=2\right)$.

Table 1 Characteristics of OpEN-CirCuit Magnetic Field

\begin{tabular}{c|c}
\hline Harmonic Orders & Rotating speed \\
\hline$n_{\mathrm{r}}$ & $w_{\mathrm{r}}$ \\
\hline$n_{\mathrm{f}}-n_{\mathrm{r}}$ & $\frac{n_{\mathrm{r}} w_{\mathrm{r}}}{n_{\mathrm{f}}-n_{\mathrm{r}}}$ \\
\hline$n_{\mathrm{f}}-n_{\mathrm{r}}$ & $\frac{n_{\mathrm{r}} w_{\mathrm{r}}}{n_{\mathrm{f}}+n_{\mathrm{r}}}$ \\
\hline
\end{tabular}

Fig. 1(b) shows a 6-slot PM vernier machine with 12 auxiliary teeth. Similarly, the number of auxiliary teeth $n_{\mathrm{a}}$ connected to each stator main tooth can be three, four or five. Therefore, the total number of auxiliary teeth or fieldmodulated teeth $n_{\mathrm{f}}$ equals to $n_{\mathrm{a}}{ }^{*} Q$, where $Q$ is the number of primary slots for the winding. It should be noted that the number of PM rotor pole-pairs $n_{\mathrm{r}}$ and stator winding pole-pair number $n_{\mathrm{s}}$ has a set relationship. The following relation has to be met.

$$
\begin{aligned}
& n_{f}=n_{a} * Q \\
& n_{s}=n_{f} \pm n_{r}
\end{aligned}
$$

The working principle of PM vernier machine is based on the field modulation effect, with the auxiliary teeth acting as the field modulator. According to the analysis in [1], a higher torque would be generated if the constraint of $n_{\mathrm{s}}=n_{\mathrm{f}}-n_{\mathrm{r}}$ can be met. A simple MMF-Permeance model is used for illustrating the field modulation effect in the PM vernier machine.

The Magnetic Motive Force (MMF) generated by the PM rotor shown in Fig. 2, whose Fourier series can be written as

$$
F(\theta, t)=\sum_{i=1}^{\infty} F_{P M i} \sin \left[n_{r} w_{r} t-(2 i-1) n_{r} \theta\right]
$$

where $F_{\mathrm{PMi}}$ is the amplitude of $i$-th harmonic; $\theta$ is the mechanical angle; $w_{\mathrm{r}}$ is the mechanical speed.

For a regualr PM vernier machine with evenly distributed auxiliary teeth, the airgap permeance of field modulation teeth is evenly distributed, as in Fig. 3. Hence, the airgap permeance can be expressed as Fourie series.

$$
P(\theta)=P_{0}+\sum_{j=1}^{\infty} P_{j} \cos \left(j n_{f} \theta\right)
$$

where $P_{0}$ is the average airgap permeance while $P_{\mathrm{j}}$ is the amplitude of $i$-th harmonic airgap permeance; $\theta_{0}$ is the initial mechanical angle.

Therefore, due to the modulation of auxiliary teeth, a complex magnetic field with rich space harmonics is generated. By multiplying the airgap permeance and MMF generated by the PM rotor, the open-circuit magnetic field can be deduced.

$$
\begin{aligned}
B(\theta, t)= & P_{0} \sum_{i=1}^{\infty} F_{P M i} \sin \left[n_{r} w_{r} t-(2 i-1) n_{r} \theta\right] \\
& +\sum_{i=1}^{\infty} F_{P M i} \sin \left[n_{r} w_{r} t-(2 i-1) n_{r} \theta\right] \\
& * \sum_{j=1}^{\infty} P_{j} \cos \left(j n_{f} \theta\right)
\end{aligned}
$$

When ignoring the higher order harmonics, the airgap magnetic field can be formulated as

$$
\begin{aligned}
B(\theta, t)=P_{0} & F_{P M 1} \sin \left[n_{r} w_{r} t-n_{r} \theta\right] \\
& +\frac{1}{2} F_{P M 1} P_{1}\left(\sin \alpha_{1}+\sin \alpha_{2}\right)
\end{aligned}
$$

where

$$
\begin{aligned}
& \alpha_{1}=n_{r} w_{r} t+\left(n_{f}-n_{r}\right) \theta \\
& \alpha_{2}=n_{r} w_{r} t-\left(n_{f}-n_{r}\right) \theta
\end{aligned}
$$

It can be obervered that three field harmonics of $n_{\mathrm{r}}, n_{f}-$ $n_{r}$ and $n_{f}+n_{r}$ are produced, and they are rotating in different directions. All the field harmonics have been summarized in Table 1.

\section{B. Open-Circuit Back-EMF and Electromagnetic Torque}

According to the winding function, the no-load flux linkage and winding function can be written as

$$
\varphi_{m}=r_{g} L_{e f} \int_{0}^{2 \pi} B(\theta, t) N(\theta) d \theta
$$




$$
N(\theta)=\sum_{v=1}^{\infty} \frac{2 N_{s} k_{w v}}{v \pi} \cos (v \theta)
$$

where $r_{\mathrm{g}}$ and $L_{\mathrm{ef}}$ is the airgap radius and effective axial length of the machine, respectively; $k_{\mathrm{wv}}$ is the winding factor of $v_{\mathrm{th}}$ harmonic, $N_{\mathrm{s}}$ is the number of series turns per phase.

By substituting (6) and (8) into (7), the instantaneous opencircuit flux linkage per-phase winding can therefore be formalized as

where

$$
\varphi_{m}=\varphi_{m 1}+\varphi_{m 2}
$$

$$
\begin{gathered}
\varphi_{m 1}=2 r_{g} L_{e f} N_{s} F_{P M i} P_{0} \frac{k_{w n_{r}}}{n_{r}} \sin \left(n_{r} w_{r} t\right) \\
\varphi_{m 2}=r_{g} L_{e f} N_{s} F_{P M 1} P_{1}\left(\frac{k_{w\left(n_{f}-n_{r}\right)}}{n_{f}-n_{r}}\right. \\
\left.-\frac{k_{w\left(n_{f}+n_{r}\right)}}{n_{f}+n_{r}}\right) \sin \left(n_{r} w_{r} t\right)
\end{gathered}
$$

Therefore, the instantaneous open-circuit back EMF induced in each phase can be expressed as

$$
\begin{gathered}
e(t)=r_{g} L_{e f} N_{s} w_{r} F_{P M 1} \cos \left(n_{r} w_{r} t\right)\left(2 k_{w n_{r}} P_{0}+\frac{n_{r}}{n_{s}} k_{w n_{s}} P_{1}\right. \\
\left.-\frac{n_{r}}{n_{f}+n_{r}} k_{w\left(n_{f}+n_{r}\right)} P_{1}\right)
\end{gathered}
$$

Since the higher the harmonic order, the lower the amplitude, the high order harmonics EMF can be neglected. Hence, the back EMF is written as

$$
\begin{aligned}
e(t)= & r_{g} L_{e f} N_{s} w_{r} \cos \left(n_{r} w_{r} t\right)\left\{2 k_{w n_{r}} F_{P M 1} P_{0}+\right. \\
& \left.G_{r} k_{w n_{s}} F_{P M 1} P_{1}\right\}
\end{aligned}
$$

where $G_{\mathrm{r}}$ is the gear ratio of the PM vernier machine.

$$
G_{r}=\frac{n_{r}}{n_{s}}
$$

Thus, the electromagnetic torque can be expressed as

$$
T=\frac{5}{2} r_{g} L_{e f} N_{s} w_{r}\left\{2 k_{w n_{r}} F_{P M 1} P_{0}+G_{r} k_{w n_{s}} F_{P M 1} P_{1}\right\}
$$

Compared with conventioanl PM synchronous machine, an additional component in both EMF and electromagnetic torque has been generated and their amplitude is proportional to the gear ratio. This is the inherent reason that the PM vernier machine has a higher toque than the conventional PM synchronous machine.

\section{PROPOSED PMV MACHINE WITH Fractional SLOT TWO-SLOT PITCH WINDING}

It has been derived from the previous section that the EMF and electromagnetic torque are propotional to the gear ratio and winding factor of each harmonic component. For a specific number of field-modulated teeth $n_{\mathrm{f}}$, the conventional ISDW PM vernier machine would have the highest gear ratio and consequently highest torque due to their lower winding pole numbers, while FSCW PM vernier machine is characterized by the lowest gear ratio and consequently lowest torque due to their higher winding pole numbers. The higher the gear ratio, the higher the output torque.
Fig. 4 shows the phasor diagram of conventional surfacemounted PM machine with a rotor pole-pair number of $n_{\mathrm{r}}$ under $I_{\mathrm{d}}=0$ control method, where $L_{\mathrm{q}}$ and $E_{0}$ is the inductance and back EMF, respectively. If the influence of the stator resistance is neglected, the power factor can be expressed as (14). For a PM vernier machine with the same rotor, its inductance is $n_{\mathrm{r}} / n_{\mathrm{s}} * L_{\mathrm{q}}\left(G_{\mathrm{r}} L_{\mathrm{q}}\right)$ which can be derived from the winding function method, and its back EMF is $k_{\mathrm{c}} E_{0}$, where $k_{\mathrm{c}}$ is the EMF amplification factor. The factor $k_{\mathrm{c}}$ is normally less than 2 and usually smaller than gear ratio $G_{\mathrm{r}}$. This is mainly because of two reasons. First, the magnitude of space harmonics after field modulation is relatively low; second, the flux leakage between poles is significant due to the high rotor pole number and open slot structure. Therefore, the power factor of the PM vernier machine with a rotor pole-pair number of $n_{\mathrm{r}}$ can be expressed in (15). An extra factor of $G_{\mathrm{r}} / k_{\mathrm{c}}$, normally higher than 2 , is added to an item in the denominator. It is obvious that the power factor has an inversely proportional relationship with gear ratio, which means the higher the gear ratio, the lower the power factor.

$$
\begin{gathered}
\cos \varphi=\frac{E_{0}}{\sqrt{E_{0}^{2}+\left(w L_{q} I_{q}\right)^{2}}}=\frac{1}{\sqrt{1+\left(\frac{w L_{q} I_{q}}{E_{0}}\right)^{2}}} \\
\cos \varphi=\frac{1}{\sqrt{1+\left(\frac{G_{r} w L_{q} I_{q}}{k_{c} E_{0}}\right)^{2}}}=\frac{1}{\sqrt{1+\left(\frac{G_{r}}{k_{c}} \frac{w L_{q} I_{q}}{E_{0}}\right)^{2}}}
\end{gathered}
$$

The PM vernier machine with ISDW configuration has a higher gear ratio and consequently higher output torque but with a lower power factor while the PM vernier machine with FSCW configuration is the on the contrary. Therefore, in this section, a five-phase PM vernier machine with fractional-slot two-slot pitch winding is proposed, which provides a trade-off between FSCW and ISDW configuration. Fig. 5 shows the five-phase PM vernier machine with a stator pole-pair number of 2. The two-slot pitch winding configuration is derived from the stator shifting concept and can be obtained by doubling the slot numbers of the conventional five-phase FSCW configuration [13] [14]. Several applicable slot-pole combinations for a balanced five-phase PM vernier machie with two-slot pitch fractional-slot winding can be summarized, as in Table 2 and Table 3.

Taking the proposed 10S-4P PM vernier machine in Fig. 5 , which means $Q=10, n_{\mathrm{f}}=20, n_{\mathrm{r}}=18, n_{\mathrm{s}}=2$, as an example, the open-circuit air-gap flux density is calculated and its FFT distribution is studied, as in Fig. 6 and Fig. 7. It is seen that the primary harmonics developed are the $2^{\text {nd }}, 18^{\text {th }}$, and $38^{\text {th }}$, which is in accordance with the theoretical analysis.

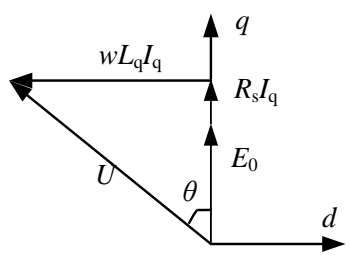

(a)

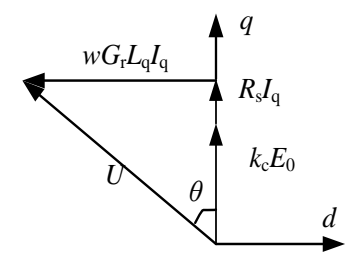

(b)
Fig. 4. Phasor diagram (a) conventional PM machine with a rotor pole-pair number of $n_{\mathrm{r}}$ (b) PM vernier machine with a rotor polepair number of $n_{\mathrm{r}}$ 
Table 2 ApPlicable Slot-Pole Combinations for Five-Phase PM VERNIER MACHINE WITH $Q=10$

\begin{tabular}{c|c|c|c|c|c|c}
\hline & \multicolumn{6}{|c}{$Q=10$} \\
\hline & \multicolumn{3}{|c}{$n_{\mathrm{f}=20}$} & \multicolumn{3}{c}{$n_{\mathrm{f}=30}$} \\
\hline$n_{\mathrm{s}}$ & $n_{\mathrm{r}}$ & $k_{\mathrm{W}}$ & GR & $n_{\mathrm{r}}$ & $k_{\mathrm{W}}$ & GR \\
\hline 2 & 18 & 0.904 & 9 & 28 & 0.904 & 14 \\
\hline 3 & 17 & 0.939 & 5.7 & 27 & 0.939 & 9 \\
\hline
\end{tabular}

Table 3 Applicable Slot-Pole Combinations for Five-Phase PM VERNIER MACHINE WITH $Q=20$

\begin{tabular}{c|c|c|c|c|c|c}
\hline & \multicolumn{6}{|c}{$Q=20$} \\
\hline & \multicolumn{3}{|c|}{$n_{\mathrm{f}=40}$} & \multicolumn{3}{c}{$n_{\mathrm{f}}=60$} \\
\hline$n_{\mathrm{s}}$ & $n_{\mathrm{r}}$ & $k_{\mathrm{w}}$ & GR & $n_{\mathrm{r}}$ & $k_{\mathrm{w}}$ & GR \\
\hline 4 & 36 & 0.904 & 9 & 56 & 0.904 & 14 \\
\hline 6 & 34 & 0.939 & 5.7 & 54 & 0.939 & 9 \\
\hline
\end{tabular}

Table 4 Combination OF SLOT-PoLE/Winding

\begin{tabular}{c|c|c|c|c|c|c}
\hline & Combinations & $n_{\mathrm{f}}$ & $n_{\mathrm{s}}$ & $n_{\mathrm{r}}$ & $k_{w}$ & $G R$ \\
\hline ISDW & $10 \mathrm{~S}-2 \mathrm{P}$ & 20 & 1 & 19 & 0.95 & 19 \\
\hline \multirow{2}{*}{$\begin{array}{c}\text { Proposed two- } \\
\text { slot pitch }\end{array}$} & $10 \mathrm{~S}-4 \mathrm{P}$ & 20 & 2 & 18 & 0.90 & 9 \\
\cline { 2 - 7 } & $10 \mathrm{~S}-6 \mathrm{P}$ & 20 & 3 & 17 & 0.94 & 5.7 \\
\hline \multirow{2}{*}{ FSCW } & $10 \mathrm{~S}-8 \mathrm{P}$ & 20 & 4 & 16 & 0.95 & 4 \\
\cline { 2 - 7 } & $10 \mathrm{~S}-12 \mathrm{P}$ & 20 & 6 & 14 & 0.95 & 2.3 \\
\hline
\end{tabular}

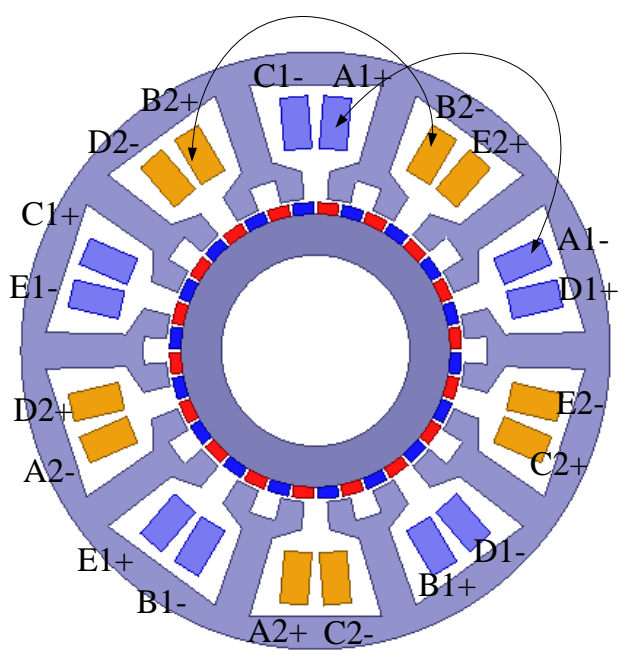

Fig. 5 Proposed 10S-4P Five-phase PM vernier machine with twoslot pitch winding $\left(n_{\mathrm{f}}=20, n_{\mathrm{r}}=18, n_{\mathrm{s}}=2, y_{\mathrm{s}}=2\right)$

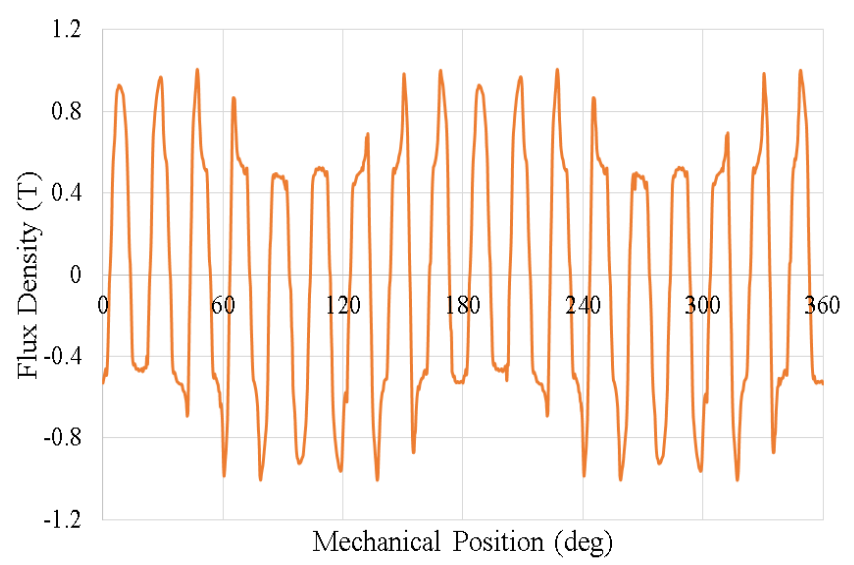

Fig. 6 Flux density of 10/20/18/2 FEA model
Fig. 8 illustrates the variation of open-circuit back EMF versus the magnet thickness. It is seen that the EMF does not keep increasing when magnet thickness increases. The high magnet thickness may result in EMF reduction. This is different from the case of conventional PM synchronous machine. In fact, this phenomenon is reasonable, as the airgap permeance is inversely proportioanl to the magnet thickness, a higher magnet thickness may reduce the fundamental airgap permeance. A similar trend can be found in the electromagnetic torque, as in Fig. 9. An optimal magnet thickness of $2 \mathrm{~mm}$ exists in terms of generating high back EMF and output torque.

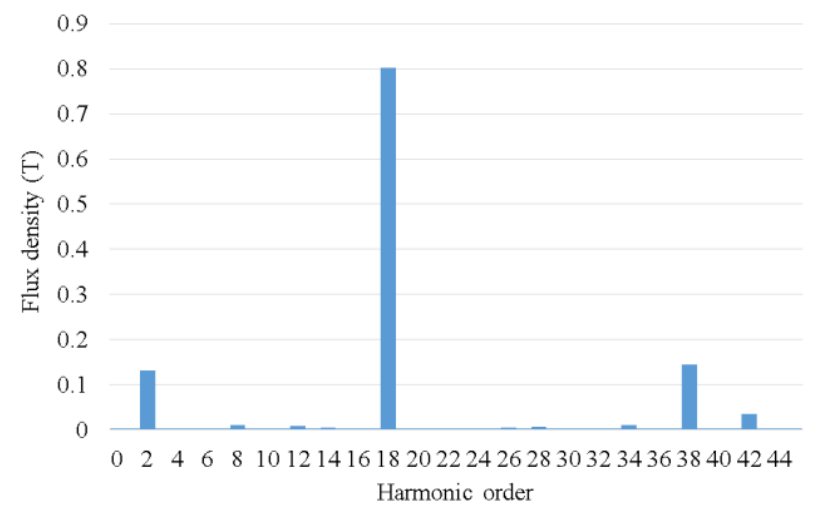

Fig. 7 FFT distribution of flux density of 10/20/18/2 FEA model

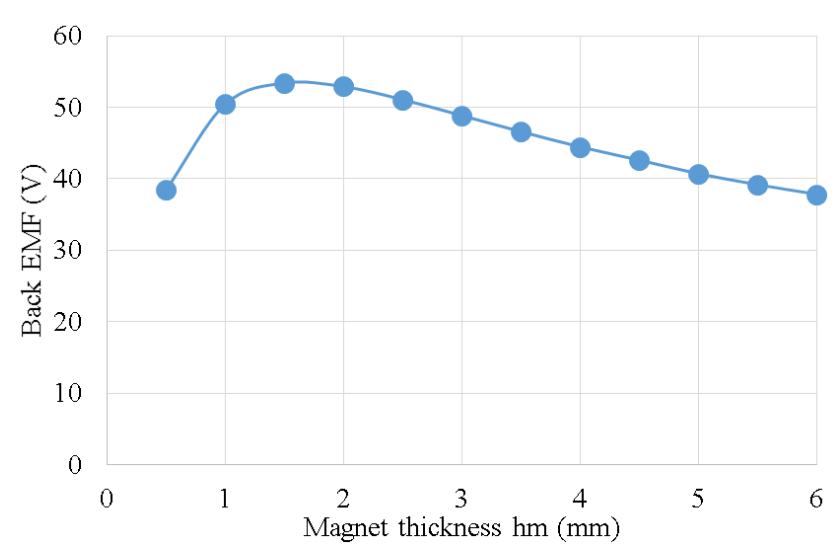

Fig. 8 Open-circuit back EMF versus magnet thickness for 10/20/18/2 PM vernier machine

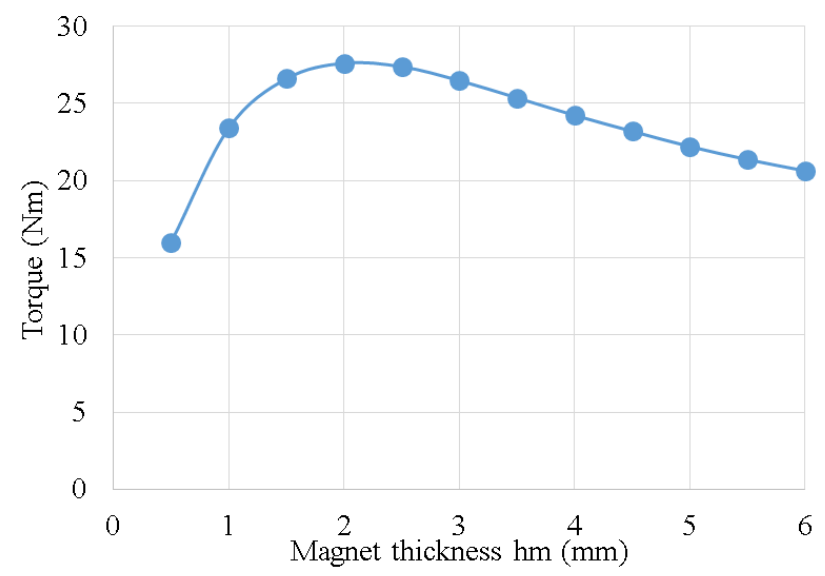

Fig. 9 Electromagnetic torque versus magnet thickness for10/20/18/2 PM vernier machine 


\section{PERFORMANCE COMPARISON OF PM VERNIER} MACHINES WITH DIFFERENT WINDING CONFIGURATIONS

In this section, the PM vernier machines with conventional ISDW and FSCW are analyzed and compared with the proposed PM vernier machines with two-slot pitch fractional slot winding, as illustrated in Fig. 10. Five PM vernier machine topologies will be studied, and their gear ratio features are summaried in Table 4. The design speficiations are summarized in Table 5.

To make a fair comparison, the slot numbers and main dimensions such as outer diameter and stack length are kept the same. The rotor diameter, pole ratio of auxiliary teeth, and magnet thickness are optimised under the same current density.

The open-circuit back EMFs of these five PM vernier machines are given in Fig. 11. It is seen that the amplitude of EMF is directly proportional to the gear ratio. The higher the gear ratio (the stronger the field modulation effect), the higher the back EMF. The 10S-2P ISDW PM vernier machine topology has the highest back EMF due to its highest gear ratio, while the conventional 10S-12P FSCW PM vernier machine has the lowest back EMF. However, the proposed $\mathrm{PM}$ vernier machine with two-slot pitch winding such as 10S$4 \mathrm{P}$ and $10 \mathrm{~S}-6 \mathrm{P}$ have relatively higher EMF.

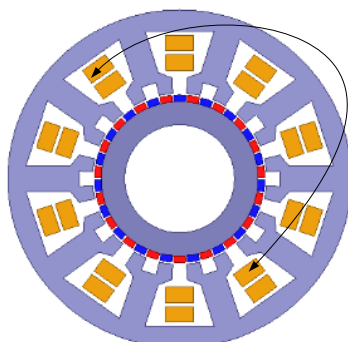

(a)

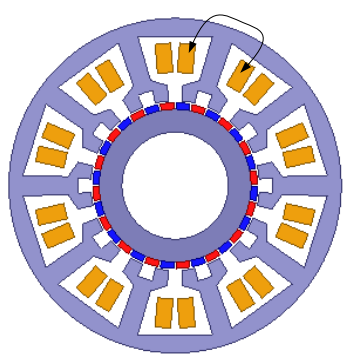

(c)

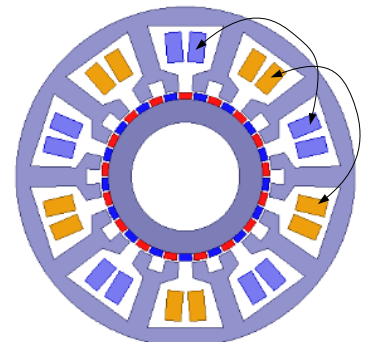

(b)

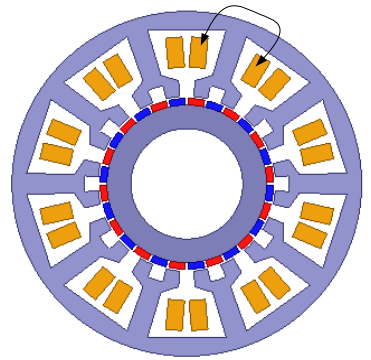

(d)
Fig. 10 Several PM vernier machines with different winding configurations (a) $10 \mathrm{~S}-2 \mathrm{P}, n_{\mathrm{f}}=20, n_{\mathrm{r}}=19, n_{\mathrm{s}}=1, y_{\mathrm{s}}=5$ ( $y_{\mathrm{s}}$ is slot pitch); (b) proposed 10S-6P, $n_{\mathrm{f}}=20, n_{\mathrm{r}}=17, n_{\mathrm{s}}=3, y_{\mathrm{s}}=2$; (c) $10 \mathrm{~S}-8 \mathrm{P}, n_{\mathrm{f}}=20$, $n_{\mathrm{r}}=16, n_{\mathrm{s}}=4, y_{\mathrm{s}}=1$; (d) $10 \mathrm{~S}-12 \mathrm{P}, n_{\mathrm{f}}=20, n_{\mathrm{r}}=14, n_{\mathrm{s}}=6, y_{\mathrm{s}}=1$;

Table 5 Design Specification of the PM Vernier Machines

\begin{tabular}{l|c|l|c}
\hline Parameter & Data & Parameter & Data \\
\hline $\begin{array}{l}\text { Stator outer } \\
\text { diameter }(\mathrm{mm})\end{array}$ & 130 & Stator core & DW315-50 \\
\hline $\begin{array}{l}\text { Stack length } \\
(\mathrm{mm})\end{array}$ & 85 & Rotor core & DW315-50 \\
\hline $\begin{array}{l}\text { Airgap length } \\
(\mathrm{mm})\end{array}$ & 0.8 & Magnet & $\mathrm{N} 45 \mathrm{SH}$ \\
\hline $\begin{array}{l}\text { Rated speed } \\
(\mathrm{rpm})\end{array}$ & 600 & $\begin{array}{l}\text { Rated current } \\
\text { density }\left(\mathrm{A} / \mathrm{mm}^{2}\right)\end{array}$ & 5 \\
\hline
\end{tabular}

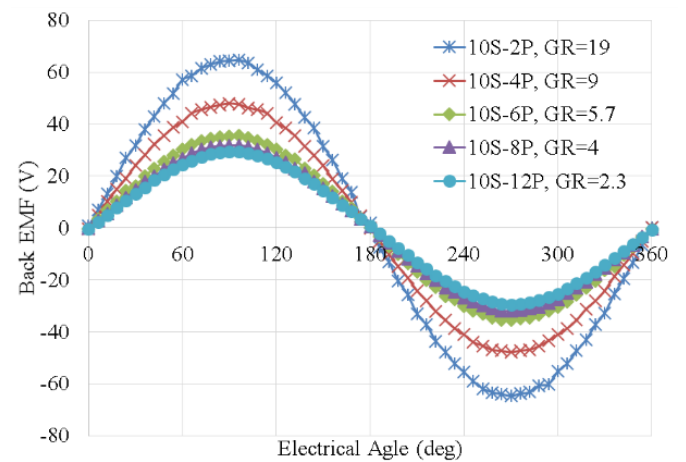

Fig. 11 Back EMF waveforms of the five PM vernier machines

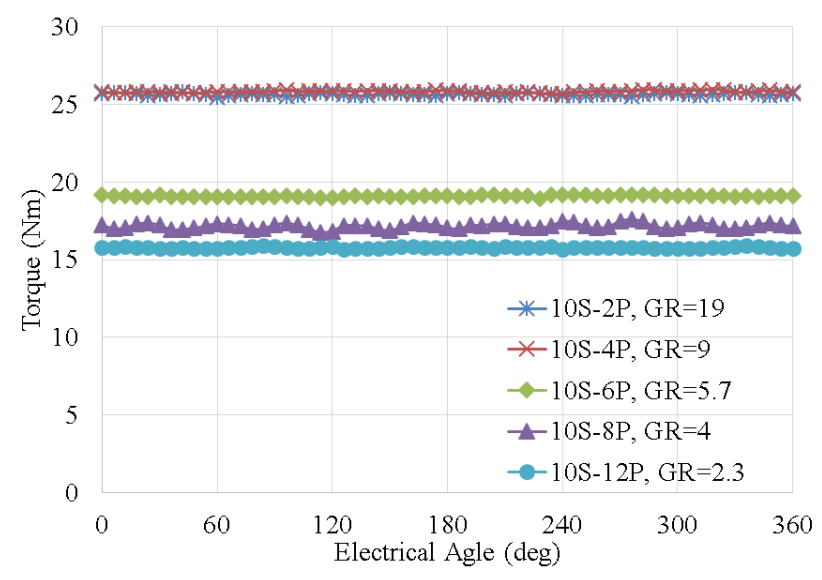

Fig. 12 Electromagnetic torque of the five PM vernier machines under rated current

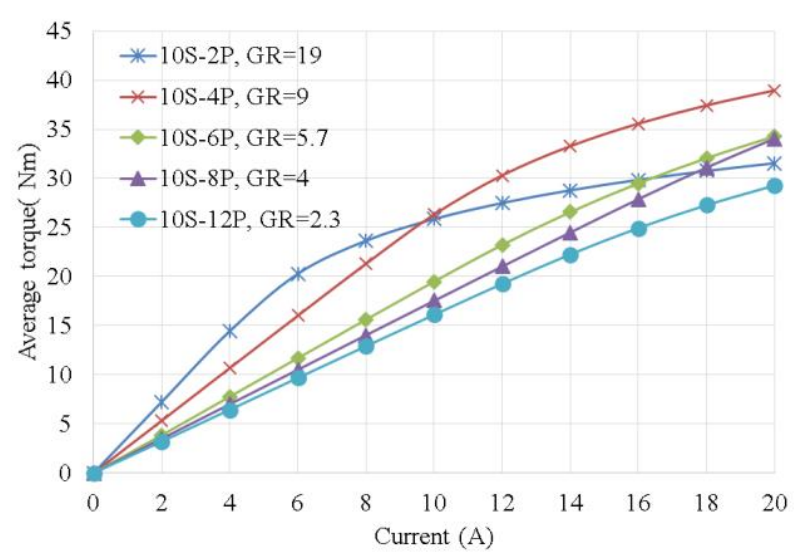

Fig. 13 Average torque versus current for the five PM vernier machines

Fig. 12 shows the electromagnetic torque waveforms under rated current of $10 \mathrm{~A}$ (rated current density of $5 \mathrm{~A} / \mathrm{m}^{2}$ ). A similar trend as EMF can be found. The higher the gear ratio, the higher the output torque. One can note that the conventional 10S-2P ISDW and the proposed 10S-4P PM vernier machine have almost the same average torque of 27 $\mathrm{Nm}$, although the former has a much higher gear ratio and open-circuit EMF. The PM vernier machine with FSCW have lower torque while the proposed PM vernier machines have relatively higher torque. In addition, the average torque of these PM vernier machine versus the current are shown in Fig. 13. It can be observed that saturation level is related with gear ratio. The higher the gear ratio, the higher the saturation level. The ISDW PM vernier machine with highest gear ratio goes into deep saturation when the current increases, implying a 
poor overload capability. The proposed PM vernier machines with two-slot pitch winding such as 10S-4P and 10S-6P have a medium saturation level while keeping a higher output torque.

The power factor variations with current are illustrated in Fig. 14. It can be found that the higher the gear ratio, the lower the power factor. The proposed PM vernier machines with two-slot pitch winding such as 10S-4P and 10S-6P have a medium power factor of about 0.46 .

Table 6 summarized the performance comparison between the five combinations. In all, it can be concluded that the proposed PM vernier machines with two-slot pitch winding such as $10 \mathrm{~S}-4 \mathrm{P}$ and $10 \mathrm{~S}-6 \mathrm{P}$ are promising candidates in the PM vernier machine topologies. It has a relatively higher output torque while still keeping a slightly higher power factor. Therefore, the proposed PM vernier machines with two-slot pitch winding can be seen as a trade-off solution between conventional ISDW and FSCW PM vernier machines.

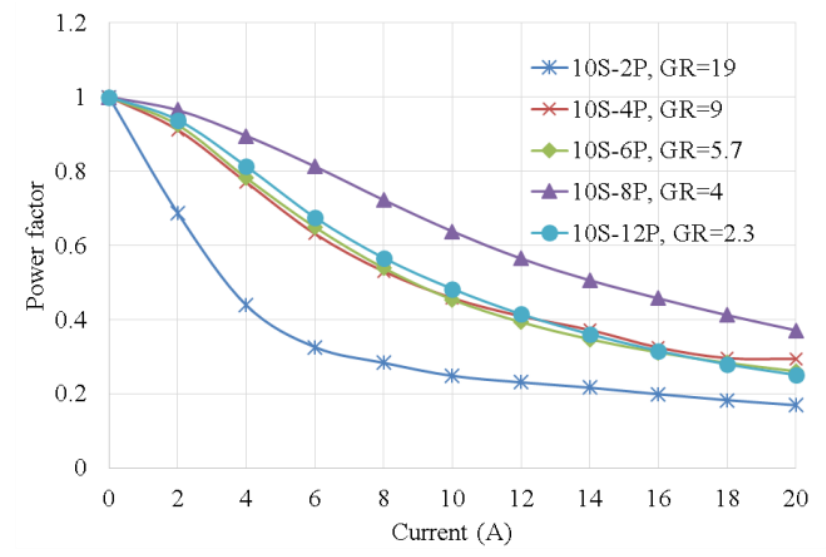

Fig. 14 Power factor of the five PM vernier machines

Table 6 Comparison of performance under rated current

\begin{tabular}{c|c|c|c}
\hline & Combinations & $\begin{array}{c}\text { Average } \\
\text { torque }(\mathrm{Nm})\end{array}$ & $\begin{array}{c}\text { Power } \\
\text { factor }\end{array}$ \\
\hline ISDW & $10 \mathrm{~S}-2 \mathrm{P}$ & 25.9 & 0.25 \\
\hline \multirow{2}{*}{$\begin{array}{c}\text { Proposed two- } \\
\text { slot pitch }\end{array}$} & $10 \mathrm{~S}-4 \mathrm{P}$ & 26.3 & 0.46 \\
\cline { 2 - 4 } & $10 \mathrm{~S}-6 \mathrm{P}$ & 19.5 & 0.45 \\
\hline \multirow{2}{*}{ FSCW } & $10 \mathrm{~S}-8 \mathrm{P}$ & 17.5 & 0.64 \\
\cline { 2 - 4 } & $10 \mathrm{~S}-12 \mathrm{P}$ & 16.1 & 0.48 \\
\hline
\end{tabular}

\section{CONCLUSIONS}

This paper proposed a five-phase PM vernier machine with two-slot pitch fractional slot winding. The operational principle and theoretical equations have been derived. The PM vernier machines performance comparison between proposed two-slot pitch winding and conventional ISDW and FSCW configuration demonstrated the superiority of the proposed $\mathrm{PM}$ vernier machine with two-slot pitch winding in terms of torque capability and power factor. This proves that the proposed PM vernier machines with two-slot pitch winding is a trade-off solution between ISDW and FSCW configuration PM vernier machine.

\section{ACKNOWLEDGMENT}

This work is funded by the INNOVATIVE doctoral programme. The INNOVATIVE programme is partially funded by the Marie Curie Initial Training Networks (ITN) action (project number 665468) and partially by the Institute for Aerospace Technology (IAT) at the University of Nottingham.

\section{REFERENCES}

[1] A. Toba and T. A. Lipo, "Generic torque-maximizing design methodology of surface permanent-magnet vernier machine," IEEE Trans. Ind. Appl., vol. 36, no. 6, pp. 1539-1546, Nov.2000.

[2] B. Kim and T. Lipo, "Operation and design principles of a PM Vernier motor," IEEE Trans. Ind. Appl., vol. 50, no. 6, pp. 3656-3663, Nov./Dec. 2014

[3] D. Li, R. Qu, J. Li, L. Xiao, L. Wu, and W. Xu, "Analysis of torque capability and quality in Vernier permanent-magnet machines," IEEE Trans. Ind. Appl., vol. 52, no. 1, pp. 125-135, 2016.

[4] J. Li, K. Chau, J. Jiang, C. Liu, and W. Li, "A new efficient permanentmagnet Vernier machine for wind power generation," IEEE Trans. Magn., vol. 46, no. 6, pp.1475-1478, Jun. 2010.

[5] X. Li, K. T. Chau, and M. Cheng, "Comparative analysis and experimental verification of an effective permanent-magnet vernier machine,” IEEE Trans. Mag., doi: 10.1109/TMAG.2014.2359853

[6] T. Zou, D. Li, R. Qu, D. Jiang, and J. Li, “Advanced high torque density PM vernier machine with multiple working harmonics," IEEE Trans. Ind. Appl., vol. 56, no. 3, pp. 5295-5304, 2017.

[7] W. Liu, L. Sun, and T.A. Lipo, "On the Scaling of Consequent Pole Vernier Machines With Spoke Type Magnets," 2018 IEEE Energy Conversion Congress and Exposition (ECCE), pp. 3294-3301, 2018.

[8] D. Li, R. Qu, and T. A. Lipo, "High power factor vernier permanent magnet machines," IEEE Trans. Ind. Appl., vol. 50, no. 6, pp. 36643674, Nov./Dec. 2014

[9] B. Kim and T. A. Lipo, "Analysis of a PM Vernier Motor With Spoke Structure,” IEEE Trans. Ind. Appl., vol. 52, no. 1, pp. 217-225, Jan. 2016.

[10] Z. S. Du and T. A. Lipo, "Torque Performance Comparison Between a Ferrite Magnet Vernier Motor and an Industrial Interior Permanent Magnet Machine,” IEEE Trans. Ind. Appl., pp. 2088-2097, 2017.

[11] L. Wu, R. Qu, D. Li, and Y. Gao, "Influence of pole ratio and winding pole numbers on performance and optimal design parameters of surface permanent-magnet vernier machines," IEEE Trans. Ind. Appl., vol. 51, no. 5, pp. 3707-3715, 2015.

[12] Xu L, Liu G, Zhao W, Ji J, Zhou H, Zhao W, Jiang T, “Quantitative comparison of integral and fractional slot permanent magnet vernier motors," IEEE Trans. Energy. Conv., vol. 30, no. 4, pp. 1483-1495. Dec 2015.

[13] S. Zhu, T. Cox, Z. Xu, and C. Gerada, "Novel 24-slots14-poles fractional-slot concentrated winding topology with low-space harmonics for electrical machine," The Journal of Engineering, vol. 17, pp.3784-3788, 2019.

[14] Abdel-Khalik, Ayman S., Shehab Ahmed, and Ahmed Massoud, "Application of stator shifting to five-phase fractional-slot concentrated winding interior permanent magnet synchronous machine," IET Electric Power Applications, vol. 10, no. 7, pp. 681690, 2016. 